\title{
PERCEPTION OF LIVE LECTURES BY MEDICAL STUDENTS
}

\author{
Nisha Narendran ${ }^{1}$, Lally M. S2, Rajany Jose ${ }^{3}$
}

${ }^{1}$ Assistant Professor, Department of Paediatrics, Government Medical College, Thrissur.

${ }^{2}$ Assistant Professor, Department of Pharmacology, Government Medical College, Thrissur.

${ }^{3}$ Assistant Professor, Department of Community Medicine, Government Medical College, Thrissur.

\section{ABSTRACT}

\section{BACKGROUND}

Students admitted to MBBS course from their school level are trained with regular 30/45 minutes subject hours in schools. Conventional live lectures are usually given in one-hour schedules in medical education. Thus medical students may find it difficult to change as they are trained to be attentive for maximum 45 minutes throughout their training years in school. Studies also show that the attention span of a person in a lecture is best for 20-30 minutes.

Aims- To find the perception about conventional one-hour live lectures on clinical topics among sixth semester MBBS students in Government Medical College, Thrissur. To find out perception of a shortened and edited 20-minute version of live lectures stressing "must know" aspects in clinical topics and references among the same students.

\section{MATERIALS AND METHODS}

A cross sectional descriptive study was conducted among the participants. Approval was obtained from the Institutional Research Committee. One-hour live lecture and 20 minutes lecture on 2 different topics by the same lecturer was given. A pre-validated questionnaire was administered to assess their perception with regards to both these lectures. The collected data was entered into MS Excel and analysed using Epi info version 7. Percentages were used to quantify the results.

Settings and Design- The study was conducted among sixth semester students attending Paediatrics lectures in Govt. Medical College, Thrissur.

\section{RESULTS}

Majority of participants opined that they couldn't concentrate more than half an hour on any single topic and found the 20-minute lectures incorporating the "must know" items to catch attention better, especially at noon hours. They opined that morning was a better time to attend live lectures.

\section{CONCLUSION}

There should be active intervention from the authorities to conduct mass surveys and assessments regarding integration of elearning with traditional teaching methods among medical students of our country. The region-specific changes accommodating the changing social persona of young adults have to be considered while planning the lecture schedule in medical education in our part of the world.

\section{KEYWORDS}

Medical Education, Medical Students, Lectures.

HOW TO CITE THIS ARTICLE: Narendran N, Lally MS, Jose R. Perception of live lectures by medical students. J. Evolution Med. Dent. Sci. 2017;6(23):1877-1881, DOI: 10.14260/Jemds/2017/412

\section{BACKGROUND}

Students admitted to MBBS course from their school level are straight away exposed to one-hour lectures in medical schools. There will be 2-3 lectures in a go, on most working days at noon, after a detailed clinical session till noon from 8/9 AM in morning. This is in contrast to their regular 30/45 minutes of subject hours in schools. They may find it difficult to change as they are trained to be attentive for maximum 45 minutes throughout their training years in school. Studies also show that the attention span of a person in a lecture is best for 20-30 minutes. A lecture should ideally be timed at

Financial or Other, Competing Interest: None.

Submission 11-02-2017, Peer Review 04-03-2017,

Acceptance 13-03-2017, Published 20-03-2017.

Corresponding Author:

Dr. Nisha Narendran,

Assistant Professor,

Department of Paediatrics,

Government Medical College, Thrissur.

E-mail: nnped@yahoo.com

DOI: $10.14260 /$ jemds $/ 2017 / 412$ not more than half an hour. But the tendency to cover topics in medical syllabus in a vast manner by the lecturers necessitates the need for keeping lecture duration at one hour. This has a negative impact in most students who may not be fast or avid learners. The survey itself indicated that majority of the class taking part in the survey had qualified MBBS taking 2 attempts or more. They tend to get distracted in between and lose connection with the point discussed especially when lecture prolongs to one hour. This can affect the assimilation of basic concepts in the to-be doctors. The students joining the course belong to the current generation using social media and smart phones too much. The tendency to use these gadgets even during lectures may be contributing to their distraction as well.(1),(2)

Medical students also have a tendency to do selective study for exam, which is a trait carried over from their school days. This affects the completeness of their learning as well. This tendency is dangerous in this field of education specifically. Selection of topics to learn can be avoided if all the relevant topics are taught in a concise and edited way where 'must know' aspects are highlighted in lecture hours. 
The important references can be given at the end of the planned and timed lecture so that self-study will be stimulated as well. The students assimilating the basic concepts in the shortened version of lecture may find it more interesting to refer the mentioned references as well. This idea was tested by the investigators in a group of preclinical students of MBBS as well.(2)

\section{Objectives of this Study were-}

1. To find the perception about conventional one-hour live lectures in clinical topics among sixth semester MBBS students in Government Medical College, Thrissur.

2. To find out perception of a shortened edited 20-minute version of live lectures stressing "must know" aspects in clinical topics and references among the same students.

\section{MATERIALS AND METHODS}

A cross sectional descriptive study was conducted among the participants. Approval was obtained from the Institutional Research Committee. January $1^{\text {st }}$ 2016- Feb. 28 2016 was the period of study. The study was conducted among sixth semester students attending Paediatrics lectures in Govt. Medical College, Thrissur. Informed consent was taken from the 122 participants. The participants had attended a live lecture of one hour the previous day by a lecturer in Paediatrics. A pre-validated questionnaire was administered which contained elements to assess their perception with regards to conventional one-hour live lectures after the lecturer left the classroom. The topic in Paediatrics was presented by the same lecturer in a 20 -minute format live lecture and was blinded to the purpose of the study. He/She was instructed to present it with stress on "must know" aspects of the topic with references at the end of the lecture. Then a pre-validated questionnaire was administered to the participants and responses collected. All 122 participants had attended the shorter version of lecture too. The data was entered into MS Excel and analysed using Epi info version 7. Percentages were used to quantify the results.

\section{RESULTS}

\begin{tabular}{|c|c|c|}
\hline Feature & & $\begin{array}{c}\text { Number } \\
\text { (Percentage \%) }\end{array}$ \\
\hline \multirow{4}{*}{$\begin{array}{l}\text { Age in } \\
\text { Years }\end{array}$} & 20 and Less & $4(3.28)$ \\
\hline & 21 & $25(20.49)$ \\
\hline & 22 & $93(76.23)$ \\
\hline & $>22$ & 0 \\
\hline \multirow{2}{*}{ Gender } & Male & $41(33.61)$ \\
\hline & Female & $81(66.39)$ \\
\hline \multirow{3}{*}{$\begin{array}{c}\text { Attempts in } \\
\text { Premedical } \\
\text { Entrance Exam to } \\
\text { Get Admission }\end{array}$} & 1 & $21(17.21)$ \\
\hline & 2 & $92(75.41)$ \\
\hline & $>2$ & $9(7.38)$ \\
\hline \multirow{2}{*}{$\begin{array}{l}\text { Medical Related } \\
\text { Degrees before }\end{array}$} & Yes & $3(92.46)$ \\
\hline & No & $119(97.54)$ \\
\hline \multirow{2}{*}{ Married/Single } & Yes & $3(2.46)$ \\
\hline & No & $119(97.54)$ \\
\hline \multirow{2}{*}{ Have Children } & Yes & $1(0.82)$ \\
\hline & No & 121 (99.18) \\
\hline \multirow{2}{*}{$\begin{array}{l}\text { Attempts at } \\
\text { Clearing } \\
\text { First MBBS }\end{array}$} & 1 & 121 (99.18) \\
\hline & 2 & $1(0.82)$ \\
\hline
\end{tabular}

In the present study, $47.54 \%$ admitted to being able to concentrate for 11-20 minutes of the lecture while $37.7 \%$ could extend listening from 21-30 minutes. While 1.64\% participants told they could attend without distraction for $>30$ minutes, $13.11 \%$ admitted to losing concentration within 10 minutes of lecture classes.

$66.39 \%$ of the participants felt the duration of any lecture be kept at a maximum of 30 minutes, $30.33 \%$ agreed for 45 minutes while 4 participants $(3.28 \%)$ preferred a 1 -hour lecture on any given topic.

$78.69 \%$ opined that they could attend one lecture at the most if the lecture duration was kept for 1 hour, while $20.49 \%$ could attend a maximum of two lectures if so and one participant $(0.8 \%)$ was eager to attend even up to 3 lectures at a stretch.

$63.93 \%$ agreed that a pre- and post-test scheduled with lecture would help in improving their attentiveness during lecture always. $29.51 \%$ were sceptical of the effect of those tests and commented that they could serve the purpose sometimes while $6.56 \%$ admitted that tests would never help in improving their attentiveness.

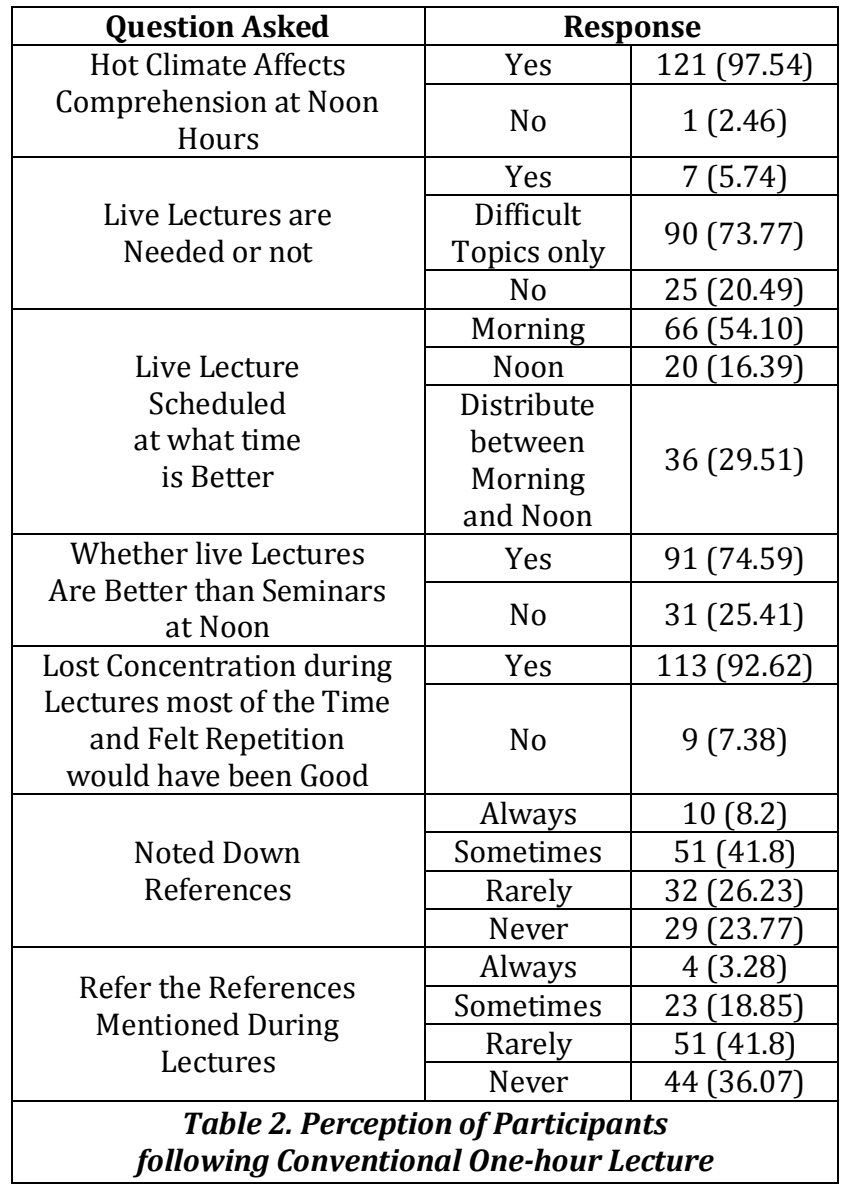

Following the 20-minute live lecture on a topic in Paediatrics, $90.16 \%$ agreed that a 20 -minute lecture concentrating on "must know" aspects caught their attention more than a 1-hour lecture does.

While $20.49 \%$ still opined that they could concentrate during the lecture only for up to 10 minutes, $54.92 \%$ could concentrate for $11-20$ minutes. $23.77 \%$ could listen for $20-30$ minutes while one participant could listen for $>30$ minutes (90 minutes). 
$77.05 \%$ of the participants agreed that pre- and post-test scheduled with a 20 -minute lecture is sure to improve their attentiveness while $3.28 \%$ disagreed. $19.67 \%$ agreed that the strategy may sometimes help them into being more attentive during the lecture. Such testing methods could improve the outcome of a lecture if the lecture span is not prolonged up to one hour. $84.43 \%$ could relate mentally to the effort needed to answer a pre- and post-test during a one-hour lecture and compare it with 20 minutes lecture duration and assessment. They were a majority in choosing 20 minutes live lecture instead of a 1-hour lecture if they were to answer pre- and post-test associated, which they had opined would improve their attentiveness during lecture. $15.57 \%$ were willing to answer a pre- and post-test with a 1-hour lecture. But considering the fact that minimum 2 lectures are scheduled at a stretch in noon hours, it might be difficult for the students to use the reform to full effect, i.e., improving attentiveness in both the scheduled lectures.

The results also indicates that the shortened version of lectures actually could motivate some students into referring further, permitting self-learning; the percentage was small and insignificant to conclude though (Table 2).

\begin{tabular}{|c|c|c|}
\hline \multirow{3}{*}{$\begin{array}{c}\text { Question Asked } \\
\text { 1-Hour Lecture not Superior } \\
\text { to } 20 \text {-minute Lecture in } \\
\text { Teacher-Student Interaction }\end{array}$} & \multicolumn{2}{|c|}{ Response } \\
\hline & Yes & 34 (27.87) \\
\hline & No & $88(72.13)$ \\
\hline \multirow{5}{*}{$\begin{array}{c}\% \text { of Lectures so far } \\
\text { Attended } \\
\text { which were } \\
\text { Thought Provoking }\end{array}$} & $<10 \%$ & $91(74.59 \%)$ \\
\hline & $11-25 \%$ & $22(18.03 \%)$ \\
\hline & $26-50 \%$ & $4(3.28 \%)$ \\
\hline & $51-75 \%$ & $4(3.28 \%)$ \\
\hline & $>75 \%$ & $1(0.82 \%)$ \\
\hline \multirow{2}{*}{$\begin{array}{c}\text { Are Lectures Better } \\
\text { at Noon Time than Seminars }\end{array}$} & Yes & 95 (77.87) \\
\hline & No & 27 (22.13) \\
\hline \multirow[b]{3}{*}{$\begin{array}{l}\text { What Time is Better to } \\
\text { Attend live Lectures }\end{array}$} & Morning & 75 (61.48) \\
\hline & Noon & $10(8.2)$ \\
\hline & $\begin{array}{l}\text { Distribute } \\
\text { Between } \\
\text { Morning and } \\
\text { Noon }\end{array}$ & 37 (30.33) \\
\hline \multirow{4}{*}{$\begin{array}{l}\text { Do you ask Doubts } \\
\text { During Lecture Class }\end{array}$} & Always & 0 \\
\hline & Sometimes & $6(4.92 \%)$ \\
\hline & Rarely & 35 (28.69) \\
\hline & Never & $81(66.39)$ \\
\hline \multirow{4}{*}{$\begin{array}{l}\text { Will Note Down References } \\
\text { Mentioned in Lecture }\end{array}$} & Always & $10(8.2 \%)$ \\
\hline & Sometimes & 44 (36.07) \\
\hline & Rarely & 35 (28.69) \\
\hline & Never & $33(27.05)$ \\
\hline \multicolumn{3}{|c|}{$\begin{array}{l}\text { Table 3. Perception of Participants } \\
\text { Following 20-minute Lecture }\end{array}$} \\
\hline
\end{tabular}

\section{DISCUSSION}

A demographic analysis was done to assess the participants' mental maturity and the possible factors which could create a deviation from the expected results for the age group. $66.39 \%$ of the participants belonging to the same class of sixth semester students were female, while $33.61 \%$ were male.(3) There is a tendency towards "feminising" the course in this study also. $3.28 \%$ were 20 years of age, $20.49 \%$ were 21 years and the majority were 22 years while they were in sixth semester. This means that majority had got into MBBS course in their second attempt which was clarified by another direct question. $75.41 \%$ were admitted to MBBS at their second attempt while $17.21 \%$ at their first attempt. $7.38 \%$ had attempted more than twice to get into the course. This per se may indicate that those getting selected to MBBS course on merit these days, are not really the fast learners. There could be gross variations in learning/concept grasping speed among students. Only 3 participants $(2.46 \%)$ had medical related degrees beforehand while $97.54 \%$ were new to the subject totally. This extra qualification and related knowledge could have made it easier to comprehend difficult medical topics but the percentage of participants was low and insignificant. 3 participants $(2.46 \%)$ were married while $97.54 \%$ were single during the study period. Only one $(0.82 \%)$ of the participants had children. These could have been potential distracting factors in lecture hours but the percentage was small and insignificant. Of the 122 participants, only one student $(0.86 \%)$ had taken 2 attempts to pass first MBBS. All others (99.18\%) cleared it in their first attempt.

Golden AS et al(4) lists the various methods to create an interesting lecture. Methods to make the lecture interesting should be adopted by the lecturer.(5) But such techniques are seldom employed by lecturers. The participants were a majority in concluding that $<10 \%$ lectures attended so far were interesting enough (Table 2).

Mustafa et al(6) had put forward the results of their multicentric survey. The participants were a majority in opining that they couldn't concentrate for more than a maximum of 30 minutes and that majority found lectures boring. The present study also confirms similar thoughts in our population of participants as well. The participants opted for live lecture itself over seminars $(77.87 \%)$ which give bit more of student participation. This may be due to the difficulty of presenting the topics in the hot noon hours as well. Instead of seminars, small activity based discussions and group discussions could generate interest and catch the attention of students thus promoting active and effective learning.(7)

Wendy Davis et al(8) have suggested many ways in which the social media can be used in medical education. The current generation of medical students were used to social media for entertainment, communication and personal purposes even in their adolescence.(9) But they point out that the biggest factor which curriculum developers worry about in incorporating these are the immense potential of distraction they can be. Even in our study, a staggering $50.41 \%$ agreed to using social media like Facebook and Whatsapp during lecture hours. $49.59 \%$ told that they never used social media during lectures yet. This upsurge of social media use by students even during lecture hours could be a factor which needs to be addressed in the future years. The tendency to blame these young adults on using such technology in day to day life is to be avoided as it is going to be the generation next era too. Instead of practices openly opposing the use, methods like mobile jammers can be kept in lecture halls. The duration of lectures can be cut short as done for this study. The lectures may be interspersed with activity based learning methods as well. Studies testing these should be conducted on a large scale basis and conclusions to 
be derived. There should be adoption of methods which use these social media for learning, in a regulated manner as well.(8) Bryner et al(10) compared the lectures conducted for 20 minutes and 50 minutes to family physicians. The study concluded that there was no statistical difference in the scores. This in fact gives a clue to the fact that there is no point in extending the lecture beyond 20 minutes. Instead the time can be used to reinforce the concepts by means of pretests and post-tests. The results of the present study too indicate that there is a pressing need for more studies and revision of methods used in lectures in medical curriculum.

Though live lecture has time tested power of staying in memory of students, mind wandering is a definite problem with the current media savvy generation. (11)

We made an attempt to gauge the learning speed according to the number of times needed to read to learn a topic as fast medium and slow learner. It was arbitrarily fixed that a fast learner learns with just one reading, medium with two attempts at reading and slow learner took 3 or more attempts. This was just for the purpose of the study. The participants assessed their learning speed on own. 63.93\% felt their speed was medium in learning, $22.13 \%$ felt they were fast learners and $13.93 \%$ felt they were slow learners. This data points to the fact that medical students need time to assimilate the ideas and also that the ideas should be presented in a structured planned manner. Clearing the medical entrance exam does not make them be classified as a fast learner by default, they need to be nurtured and cared for really well to make them be strong with their basics. This involves efficient planning and execution of the syllabus, befitting the digital era they belong to. The advantages of traditional lectures can still be tapped to greater effect with effective incorporation of e-learning methods.(12) This is important to generate an effective and knowledgeable doctor population to serve the country.

\section{CONCLUSION}

Lectures are an important teaching-learning method used in medical education.

The conventional 2 or 3 live lectures, lasting an hour on a topic each, every noon is not helping the students achieve the best they can. There should be active intervention from the authorities to conduct mass surveys and assessments regarding integration of e-learning with traditional teaching methods among medical students of our country. The regionspecific changes accommodating the changing social persona of young adults have to be considered while planning the lecture schedule in medical education in our part of the world.

\section{Recommendations Based on the Study}

The investigators find the following recommendations prudent enough to be instituted widely in medical schools to improve the assimilation of topics presented in lectures:

1. The time of lecture may be predominantly fixed and strictly insisted to be taken in morning hours when students are fresh relatively, in the day.

2. The lecture duration should be cut short to 20-30 minutes, with focus on "must know" items and mentioning references in the end. This will enable the above average students to read more in a focussed manner as well as may motivate even the slow learner into better habits of referring further.

3. There should be mobile jammers in lecture classes. This may prevent the distraction of the media savvy generation during lecture hours.

4. It is good to orient the students regarding the dangers of social media use right from the beginning of the course.

5. There should be genuine attempts from the universities to conduct trials of lectures using virtual learning environments which the media savvy generation may find useful. This may enable them to learn key concepts at their pace, at a comfortable time and place. The lectures may be watched again to stimulate the memory as needed, later too. This may enable periodic assessments of the "must know" topics which makes sure that the medical graduate is equipped with the important aspects of any given subject. This may improve the quality of the Indian Medical Graduate.

\section{REFERENCES}

[1] Rideout VJ, Foehr UG, Roberts DF. Generation M2: Media in the lives of 8 to 18 year-olds. The Kaiser HJ Family Foundation 2010:1-79.

http://kff.org/other/report/generation-m2-media-inthe-lives-of-8-to-18-year-olds/.

[2] Narendran N, Lally MS, Jose R. Social Media use and perception of live lectures by medical students. JEBMH 2017;4(16):921-4.

http://www.jebmh.com/data_pdf/Nisha Narendran final.pdf.

[3] Bleakley A. Gender matters in medical education. Med Educ 2013;47(1):59-70.

[4] Golden AS. Lecture skills in medical education. Indian J Pediatr 1989;56(1):29-34.

http://www.ncbi.nlm.nih.gov/pubmed/2583766

[5] Graffam B. Active learning in medical education: strategies for beginning implementation. Med Teach 2007;29(1):38-42.

[6] Mustafa T, Farooq Z, Asad Z, et al. Lectures in medical education: what students think? J Ayub Med Coll Abbottabad 2014;26(1):21-5.

http://www.ayubmed.edu.pk/JAMC/26-1/Zerwa.pdf.

[7] Terenzini PT, Cabrera AF, Colbeck CL, et al. Collaborative learning vs. lecture/discussion: students' reported learning gains. J Eng Educ 2001;90(1):123-30.

[8] Davis WM, Ho K, Last J. Advancing social media in medical education. CMAJ 2015;187(8):549-50. http://www.ncbi.nlm.nih.gov/pubmed/25852033.

[9] Coyne SM, Padilla-Walker LM, Howard E. Emerging in a digital world: a decade review of media use, effects and gratifications in emerging adulthood. Emerg Adulthood 2013;1(2):125-37.

http://eax.sagepub.com/lookup/doi/10.1177/21676 96813479782.

[10] Bryner CL. Learning as a function of lecture length. Fam Med 1995;27(6):379-82. 


\section{Jemds.com}

[11] Varao-Sousa TL, Kingstone A. Memory for lectures: how lecture format impacts the learning experience. PLoS One 2015;10(11):e0141587.

http://journals.plos.org/plosone/article?id=10.1371/j ournal.pone.0141587.

\section{Original Research Article}

[12] Sadeghi R, Sedaghat MM, Ahmadi FS. Comparison of the effect of lecture and blended teaching methods on students' learning and satisfaction. J Adv Med Educ Prof 2014;2(4):146-50.

http://www.pubmedcentral.nih.gov/articlerender.fcgi ?artid=4235559\&tool=pmcentrez\&rendertype $=$ abstract. 